\title{
Glucose effects on declarative and nondeclarative memory in healthy elderly and young adults
}

\author{
CAROL A. MANNING, MICHAEL W. PARSONS, ELLEN M. COTTER, and PAUL E. GOLD \\ University of Virginia, Charlottesville, Virginia
}

\begin{abstract}
Peripheral glucose ingestion enhances performance on explicit declarative verbal memory tasks in healthy elderly people. In the present experiment, healthy young and elderly adults were administered glucose $(50 \mathrm{~g})$ or saccharin followed by tests of declarative verbal memory (free recall and recognition of a word list) and a nondeclarative priming test (word-stem completion). In the elderly, glucose significantly enhanced performance on the declarative but not on the nondeclarative portions of the test. Performance by the young subjects was equivalent in the glucose and saccharin conditions. These findings, that glucose enhances memory for a declarative/explicit but not nondeclarative/implicit task, support the notion that declarative and nondeclarative memory systems are separate functional and anatomic systems.
\end{abstract}

Pharmacological enhancement of memory by glucose in rodents (Gold, 1991; White, 1991) and in healthy elderly people and people with Alzheimer's disease is now well established (Craft, Zallen, \& Baker, 1992; Craft, Murphy, \& Wenstrom, 1994; Hall, Gonder-Frederick, Chewning, Silveira, \& Gold, 1989; Manning, Hall, \& Gold, 1990; Manning, Parsons, \& Gold, 1992; Manning, Ragozzino, \& Gold, 1993; Wann, Ballard, \& Lade, 1991; cf. Gold, 1995). In a series of double-blind experiments, performance on a variety of memory tasks was facilitated by glucose ingestion in individuals with memory deficits resulting from conditions including advanced age and Alzheimer's disease. In particular, these experiments demonstrated glucose enhancement of explicit (or declarative) memory. These explicit tests emphasize conscious recollection of recently learned material (Squire, Knowlton, \& Musen, 1993). For example, relative to saccharin performance, glucose ingestion facilitated performance in healthy elderly subjects on a test of memory for narrative prose (Hall et al., 1989) and improved performance on a variety of declarative memory tasks, including word and paragraph recall, but did not affect performance on other nonmemory neuropsychological measures such as attention or motor speed (Manning et al., 1990). Glucose ingestion also improved performance in healthy middleaged people (age 40-55) on declarative verbal, visual, and associative memory tasks (Wann et al., 1991). Glucose improved paragraph recall, again a declarative task, in mildly demented probable Alzheimer patients (Craft

\footnotetext{
This research was supported by the Sandoz Foundation for Gerontological Research, the Alzheimer's Association, NIH Training Grant HD07232, NIA (AG 07648), ONR (NOOO1489-J-1216), NSF (BNS9012239), and NINDS (NS 32914). Special thanks are extended to Michelle Eng and Belinda Conley for help in manuscript preparation. Correspondence should be directed to C. A. Manning, Department of Neurology, Box 394, University of Virginia, Charlottesville, VA 22908 (e-mail: cm4r@virginia.edu).
}

et al., 1992). In moderately to severely demented probable Alzheimer patients, Manning et al. (1993) found that glucose improved performance on a variety of declarative tasks, including information learned in the experimental setting (paragraph recall) and general information (orientation) but not memory in the nondeclarative domain (word-stem completion).

There is mounting evidence for a separate memory system involving a category of learning that is distinct from explicit recall of semantic or episodic information (McAndrews, Glisky, \& Schacter, 1987; Shimamura, Salmon, Squire, \& Butters, 1987; Squire et al., 1993; Tulving \& Schacter, 1990). This nonconscious memory, called priming, involves recall of information without the subject's being made aware that (s)he is explicitly recalling previously learned information. Priming is of particular interest because performance on such tasks can be dissociated from performance on more traditional explicit memory tasks; individuals with deficits on declarative semantic tasks may demonstrate intact priming abilities (McAndrews et al., 1987; Shimamura et al., 1987). For example, amnesic individuals who have impaired declarative memory demonstrate intact priming (Cave \& Squire, 1992; Graf, Squire, \& Mandler, 1984; Musen \& Squire, 1992; Schacter, Cooper, Tharan, \& Rubens, 1991). Further evidence for a dissociation of memory types includes experiments in which patients with Huntington's disease display normal priming but impaired performance on explicit memory tasks (Bylsma, Rebok, \& Brandt, 1991; Christopher, 1991). In addition, healthy elderly people have been shown to have impaired word recall and recognition but intact priming relative to young subjects (Light \& Singh, 1987). A second line of evidence suggesting a dissociation between declarative memory and priming comes from research indicating that varying the strength of declarative memory does not affect priming (see Squire et al., 1993). Recently, a double dissociation was found in healthy elderly in which 
different types of priming tasks (word-stem completion vs. word-fragment completion) correlated with performance on traditional neuropsychological tests associated with different brain areas (frontal lobes vs. hippocampus) (Winocur, Moscovitch, \& Stuss, 1996).

To date, the effects of glucose on memory in healthy elderly individuals have been examined only in the declarative domain. The question of whether glucose facilitation of memory maps onto the declarative/nondeclarative organization of memory has yet to be examined. In severely demented Alzheimer's patients, glucose enhanced recognition of a word list but did not affect priming stem completion of the same word list (Manning et al., 1993). This dissociation suggests that glucose may promote performance on declarative tasks but not affect the separate memory system encompassing priming. Evidence that glucose does not facilitate priming in Alzheimer's patients, taken together with findings that glucose appears to be most effective as a memory modulator in healthy elderly on such tasks as memory for narrative prose and word-list recall in which there is a demonstrated age decline (unlike priming) (Craik, 1977; Drachman \& Leavitt, 1972), suggests that glucose might not enhance priming performance in healthy elderly.

Examining the effects of glucose on declarative and nondeclarative memory tasks within the same individuals provides us with the opportunity to determine whether pharmacological enhancement of memory, as evidenced by glucose, will dissociate in the same fashion (declarative vs. nondeclarative) as found in amnesic patients. In other words, does the structure of memory split into different components when based on a drug-treatment/ modulation design? If glucose facilitates both declarative and nondeclarative tasks, at least two explanations are possible: (1) glucose is broad acting and nonspecific to memory structure or (2) our current conceptualization of memory along declarative/nondeclarative lines needs modification. On the other hand, if glucose enhancement of memory dissociates along the declarative/nondeclarative distinction, this would provide additional evidence for separate memory systems.

The findings here indicate that in healthy elderly subjects, glucose enhances memory for word-list recall, a declarative verbal memory task, but not for word-stem completion, a priming task, focused on the same presentation of a word list.

\section{METHOD}

\footnotetext{
Subjects

This study used elderly and young subjects. Twenty-three elderly volunteers ( 8 males, 15 females) were recruited from the local senior citizens center, local churches, and newspaper announcements. They were between 61 and 80 years old $(M=67)$ and had an average of 15 years of education. All were in good health without evidence of dementia, as measured by Folstein mini-mental status scores of 26 or greater (Folstein, Folstein, \& McHugh, 1975), and were community dwelling. None had a history of chronic health problems or neurological disease.
}

Twenty-four undergraduates ( 8 males, 16 females) comprised the young subject group. All were enrolled in an introductory psychology course and received credit toward fulfillment of a research requirement as compensation for participation. They were between 17 and 22 years old $(M=18.6)$ and had an average of 13 years of education.

\section{Procedures}

A repeated measures design was used in which each subject served as his or her own control. Testing took place on two mornings $(0700-0900 \mathrm{~h})$ separated by 1 week. All testing was carried out individually. All subjects refrained from eating or drinking during the $8 \mathrm{~h}$ preceding testing in order to ensure that all were tested with baseline blood glucose levels. After arriving at the testing center, medical and educational information was obtained from each subject. Next, baseline blood glucose measurements were recorded using a Glucoscan 2000 meter (Lifescan, Mountain View, CA). In this procedure, one drop of blood from a finger stick is placed on an enzyme pad that is read by a reflectance meter. This procedure is relatively pain free, and no discomfort was reported. Upon completion, the subjects ingested an 8-oz lemon-flavored beverage sweetened with either $50 \mathrm{~g}$ of glucose or $23.7 \mathrm{mg}$ of saccharin. These beverages were taste matched for sweetness. Both subject and examiner were blind to condition. To maintain the double-blind status of the experiment, one examiner administered the memory measures and another obtained blood-glucose levels. Blood glucose levels were measured $15 \mathrm{~min}$ after beverage ingestion, which is the time required for significant rises in blood glucose (Hall et al., 1989; Manning et al., 1990), and twice more over the next $30 \mathrm{~min}$.

Fifteen minutes after beverage ingestion, a priming task adapted from Squire, Shimamura, and Graf (1987) was administered. For this test, 72 target words with a mean frequency of occurrence of 67 per million (Francis \& Kučera, 1982) and with between four and nine letters each were printed individually on index cards. The first three letters (the stems) were identical to at least 10 other dictionary entries, but each word had a stem unique from the other 71 target words.

First, subjects were shown 23 words ( 18 targets and 5 filler words), one at a time. They were asked to rate how well they liked each word on a 5-point scale. This was done twice with the word list presented in two different random orders. This procedure ensured that the words were semantically encoded. A card showing the choices from 1 (like extremely) to 5 (dislike extremely) was placed in front of the subject. The speed of presentation, which averaged about $5 \mathrm{sec}$ per word, was determined by the subject.

Next, priming was tested through word completion in which subjects were shown, one at a time, 29 three-letter word stems each written on an index card. The subjects were asked to complete the stem, using the first word that came to mind, and were given $3 \mathrm{sec}$ to do so. Any word except for a proper noun was acceptable. Eighteen of the stems could be completed from the list that they had just seen. Five of the 11 new stems were placed at the beginning of the list; the other 6 were spread throughout the 18 previously seen stems. The 11 new stems were used to assess baseline guessing rates- that is, to see how many words could be accurately completed despite no previous contact in the experimental context. No reference was made to the fact that this was a memory test and that some of these words could be completed by using previously seen words.

The recognition component of the task involved showing 36 words, 18 previously seen and 18 distractor words with a total possible correct of 36 . The subjects were requested to specify whether or not they had seen the word in the liking task. Following this, a measurement of the blood glucose level was obtained.

The free-recall portion of the priming task was administered next. Here, the subject was asked to write down as many words from the liking task as he/she could recall. The subjects were given as much time as they wanted; this averaged about $4 \mathrm{~min}$. A final blood glucose measurement was obtained and subjects were dismissed for the day. 
One week later, the identical procedure was repeated using the alternate beverage and equivalent test forms. The alternate test forms used identical criteria - that is, in terms of word frequency of occurrence and number of letters. Different word lists constituted the two alternate forms. This was necessary because each subject received both forms. Within each form, however, studied versus unstudied words were interchanged across subjects; that is, the composition of the 11 unstudied words and the 18 studied words was changed in a random fashion to avoid target lists' being easier to complete. Note that a nontraditional design was used in which the same word list was used for recall, priming, and recognition within a given week. This was done in order to examine the possibility of

A

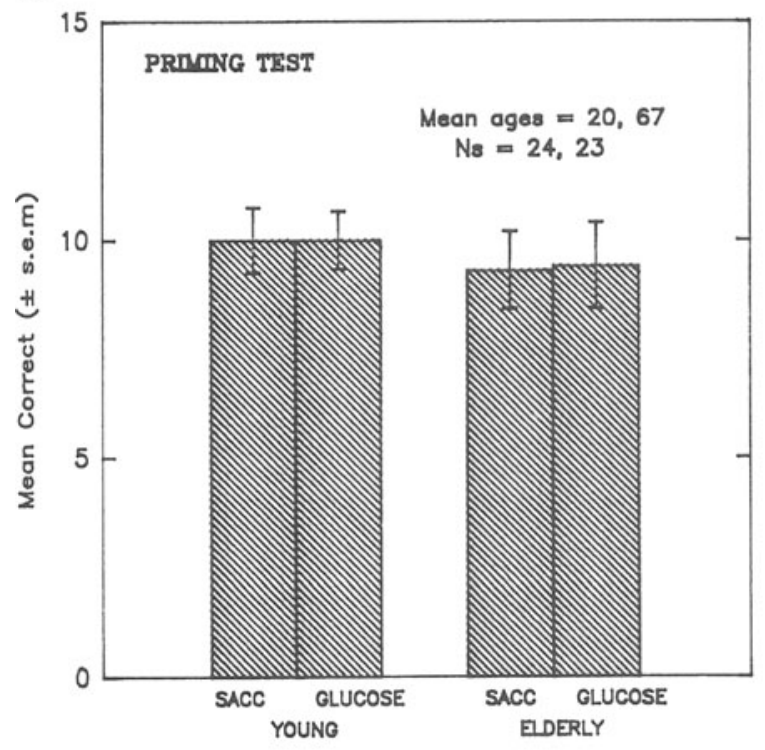

different effects of glucose on the same words, depending on the constraints of the memory strategy (recall, priming, or recognition). Since the same procedure was used in both glucose and saccharin conditions, the effects of using a single word list within conditions should have been equivalent across conditions without a glucose effect. The beverage sweetener was counterbalanced across subjects to control for order and practice effects across weeks. The same procedures were used for the young and elderly subjects.

\section{Statistical Analyses}

Data were analyzed using Wilcoxon rank comparisons of two samples (Siegel, 1956) (two-tailed) for glucose versus saccharin

B

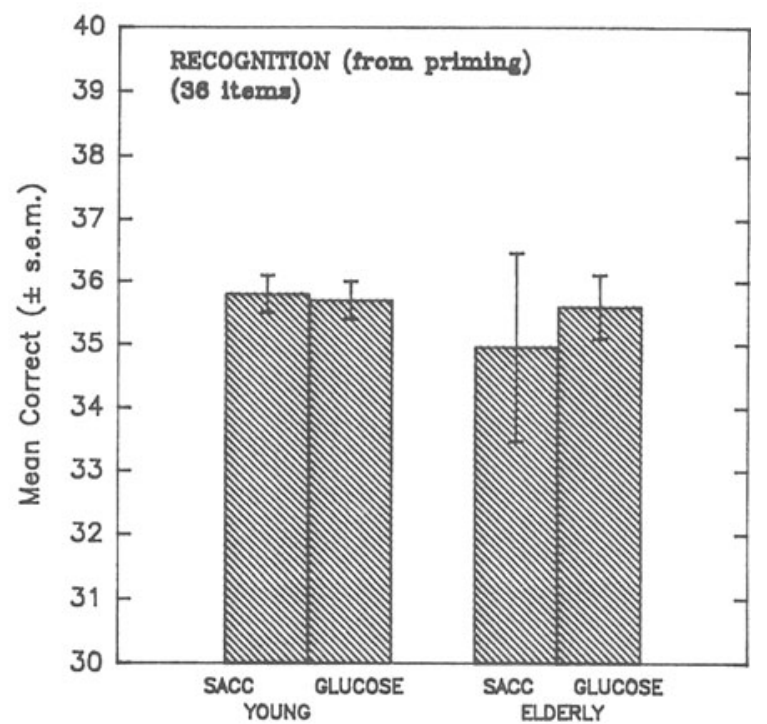

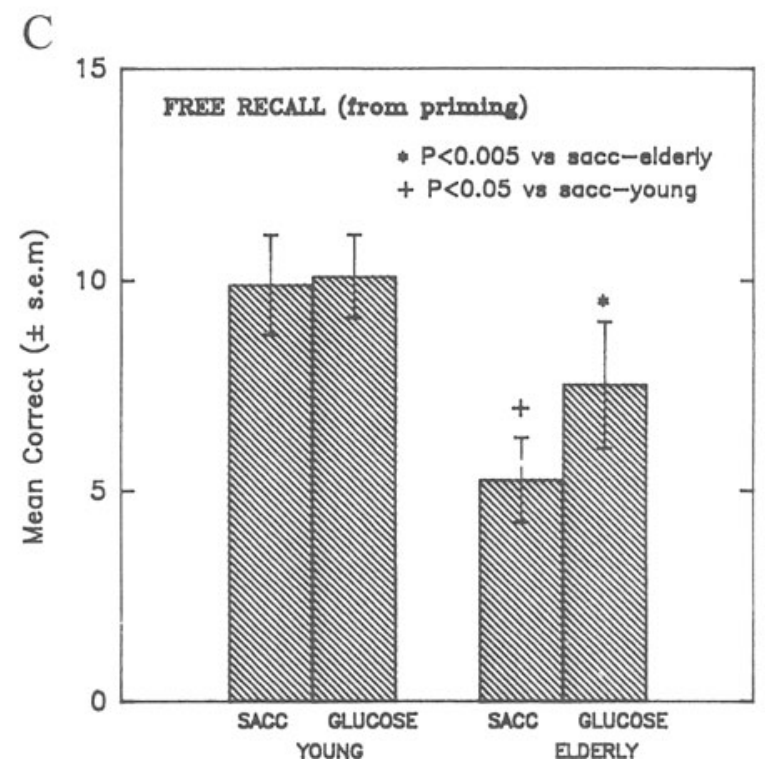

Figure 1. Mean number of items correct are presented for young and elderly in saccharin and glucose conditions in the (A) priming (stem completion), (B) word-recognition, and (C) free-recall portions of the test. Free recall was significantly $(p<.05)$ improved after glucose ingestion in the elderly. Elderly subjects recalled significantly $(p<.05)$ fewer words after saccharin ingestion than did young subjects after saccharin ingestion. Recognition (panel B) was nearly perfect for young and elderly subjects in both glucose and saccharin conditions. 
performance. Spearman rank-order correlations were used to assess reliability of the tests across conditions.

\section{RESULTS}

Priming was determined by subtracting the number of correctly completed word stems for unstudied words from the total number of completed stems. In this way, only correct completion of stems for studied words were counted as primed. As can be seen in Figure 1A, the mean priming rate for young people was $10(S D=4.9)$ in both glucose and saccharin conditions. The mean priming rate for older subjects was 9.2(8.7) and 9.3 (8.9) for saccharin and glucose, respectively. Mean baseline guessing rates, computed as the number of correctly completed stems for unstudied words, were 3.5 (1.2) and 3.3 (1.4) for saccharin and glucose, respectively, in the young people, and $3.0(2.5)$ and $3.8(2.9)$ in the older subjects.

In the elderly, glucose significantly improved free recall of the priming task word list relative to performance after saccharin ingestion (Figure 1B). Although recognition of the priming word list improved in the glucose condition, it was not statistically significant ( $p=.07$ ). However, performance on this portion of the test was nearly perfect (correct recognition of 35.6 and 34.96 out of 36 for glucose and saccharin, respectively) (Figure 1C). In the young subjects, performance was equivalent across conditions (glucose and saccharin) within each memory task-priming, recognition, and recall.

As expected, blood glucose levels rose significantly after ingestion of the glucose beverage (Figure 2). In addition, blood glucose levels were significantly higher in the elderly than in the young on both glucose and saccharin days at all measurements except for the baseline measurement on the saccharin day. Thus, glucose regulation was poorer in the elderly subjects than in the young, as noted by generally higher blood glucose levels and larger increases in blood glucose after glucose ingestion in the elderly.

\section{DISCUSSION}

The present results indicate that glucose enhances performance in explicit declarative verbal memory in healthy elderly people, but that glucose does not affect wordstem completion. The dissociation between glucose facilitation of explicit recall but not of priming supports the hypothesis that priming is independent of explicit memory (Tulving \& Schacter, 1990). This is particularly evident when taking into account that the word list for the explicit and the implicit conditions of the test comprised a single list learned at the same time. Thus, since the words were learned only once, the difference in glucose facilitation of explicit but not of implicit memory cannot be explained by different learning conditions. Likewise, glucose was administered only once during the testing protocol, eliminating administration differences as a source of enhancement of declarative but not of nondeclarative performance. Equivalent word-stem comple-
MEAN GLUCOSE LJVELS FOLLOTING BEVHRAGE INGJSTION

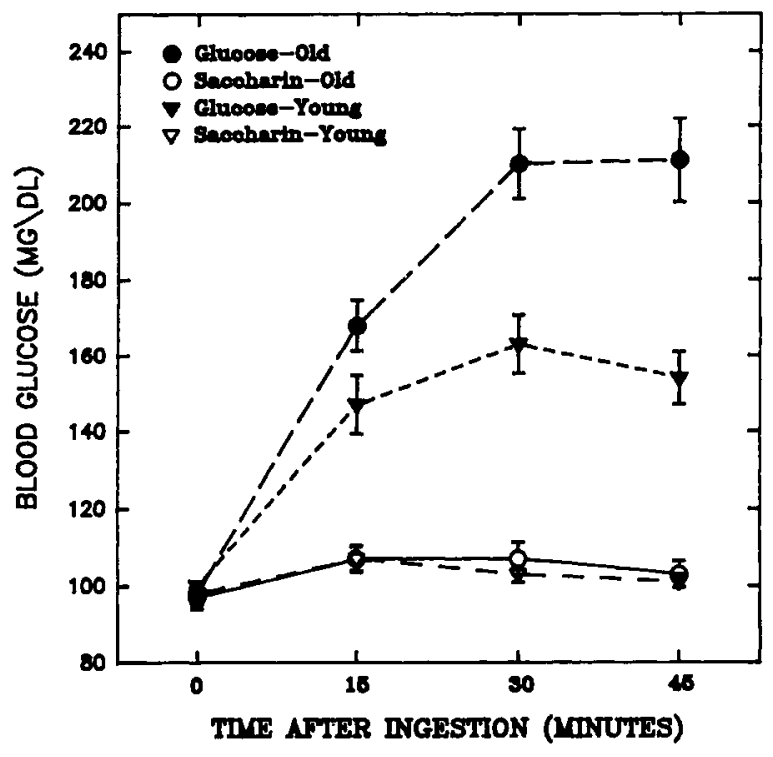

Figure 2. Mean blood glucose levels at baseline were comparable in young and elderly subjects in glucose and saccharin conditions. Mean blood glucose levels were significantly higher at all subsequent measurements when the beverage was sweetened with glucose rather than saccharin.

tion was seen in glucose and saccharin conditions without floor or ceiling effects. Therefore, there was room for improvement in priming performance if glucose had proven effective. It is also possible that glucose enhances explicit and implicit memory at different doses, a possibility that would require a full dose-response curve to evaluate; task-related dose-response differences for memory enhancement with glucose, as with other pharmacological treatments, are quite common in experiments with rodents (e.g., Gold, Vogt, \& Hall, 1986; Packard \& White, 1990).

These findings provide at least a third line of evidence indicating that implicit memory, as measured by a stemcompletion task, is a memory system distinct from declarative memory. The current results can be added to findings from studies with amnesic patients in which deficits exist in declarative but not in nondeclarative domains (Cave \& Squire, 1992; Graf et al., 1984; Musen \& Squire, 1992; Schacter et al., 1991) and from experiments in which increasing the degree of recall ability does not affect priming (Squire et al., 1993). The current cognitive conceptualization of memory into declarative/nondeclarative domains appears to remain stable across at least three types of experiments involving (1) naturally occurring pathologies, (2) manipulation of memory strength, and now (3) a drug treatment/memory modulation design.

Glucose facilitated performance on declarative verbal recall in the elderly group, providing a replication in principle of previous studies (Hall et al., 1989; Manning 
et al., 1990). Despite being an explicit/declarative verbal memory task, the word-recognition component of the test was not significantly facilitated by glucose. This may be attributed to the nearly perfect recognition scores in the elderly ( 34.96 out of 36 ), leaving little room for improvement.

This study did not provide evidence for glucose enhancement of memory in young adults. These negative findings may be a result of age-related differences in susceptibility to glucose enhancement of memory, to age differences in glucose regulation resulting in an adjustment of the glucose dose necessary for facilitation, or to age-related differences in test difficulty. Experiments using multiple doses of glucose together with tests of varying difficulty would be necessary to address this issue.

Current neurobiological evidence suggests that circulating glucose levels may interact with specific neurochemical and neuroanatomical systems in the brain. Recent findings in rodents suggest that extracellular glucose levels decrease in brain regions activated during learning (Fellows, Boutelle, \& Fillenz, 1993), suggesting that exogenous administration of glucose might ameliorate this decrease. In addition, circulating glucose levels might contribute to regulation of brain acetylcholine synthesis in aged rodents by serving as a precursor for acetyl-CoA, a substrate in acetylcholine synthesis (Gibson \& Peterson, 1981; Ricny, Tucek, \& Novakova, 1992). Such findings fit well with evidence that glucose injections augment several effects of cholinergic agonists and attenuate effects of cholinergic antagonists (cf. Gold, 1994). Glucose also attenuates the effects on memory and other behavioral measures of systemic or direct brain injections of the opiate agonist morphine (Ragozzino \& Gold, 1994; Ragozzino, Parker, \& Gold, 1992; Stone, Walser, Gold, \& Gold, 1991). Recent evidence (Ragozzino, Unick, \& Gold, 1996) indicates that glucose injections augment release of acetylcholine in the hippocampus of rats while the animals are performing a memory task; glucose had no effect on acetylcholine release in rats kept in holding cages, suggesting that glucose may act somewhat selectively when neural systems are engaged by memory tasks, and perhaps differentially so, depending on the nature of the behavioral task. While neurobiological measures such as these may contribute to the effects of glucose on cognitive functions, it is important to note that parallel information about neurotransmitters other than acetylcholine in brain regions other than the hippocampus is not available.

One interpretation of the findings of the present experiment is that activation of the neural systems mediating explicit memory creates a demand for glucose in these neural systems, while activation of the neural systems mediating implicit memory does not create such a demand in these, other, neural systems. A similar interpretation can be applied to differences in neural systems activated by retrieval of information via explicit or implicit mechanisms. The present experiment cannot distinguish effects of glucose on acquisition from those on retrieval because glucose was present at both the times of acquisition and the times of retrieval of information. However, the findings of other experiments in both humans and rodents indicate that glucose administration at the time of either acquisition or retrieval enhances learned performance (Manning, Stone, Korol, \& Gold, 1997; Stone, Rudd, \& Gold, 1990).

This study examined only one form of priming: stem completion. Future experiments examining other types of priming, in addition to procedural memory tests, are in order. These experiments would further clarify the extent of glucose's ability to facilitate memory, as well as provide information on the cognitive and neurobiological underpinnings of memory formation. Utilization of multiple implicit and explicit tasks might provide evidence for a double dissociation, thus strengthening the idea of separate memory systems.

Taken together, these findings suggest that glucose enhancement of acquisition and/or recall is subject to the nature of the method used to assess memory. This study provides replication of evidence that glucose enhances performance on explicit verbal memory tasks in healthy elderly people. However, implicit memory, as measured by word-stem completion, was unchanged after glucose ingestion in the same subjects. This dissociation between types of recall-task demand suggests that the two types of tasks may (1) utilize different neural pathways and (2) be independent of each other, although direct confirmation of separate memory systems is beyond the scope of this paper. This study did not provide evidence that glucose potentiates memory in healthy young adults. Differences in age-related susceptibility to glucose may be associated with increased difficulties with peripheral glucose regulation with aging and the inability of aged subjects to regulate optimally the neuroendocrine systems responsible for memory storage.

\section{REFERENCES}

Bylsma, F. W., ReboK, G. W., \& Brandt, J. (1991). Long-term retention of implicit learning in Huntington's disease. Neuropsychologia, 29, 1213-1221.

Cave, C. B., \& Squire, L. R. (1992). Intact and long-lasting repetition priming in amnesia. Journal of Experimental Psychology: Learning, Memory, \& Cognition, 18, 509-520.

Christopher, R. ([991). Implicit, explicit, and semantic memory functions in Alzheimer's disease and Huntington's disease. Journal of Clinical \& Experimental Neuropsychology, 13, 479-494.

Craft, S., Murphy, C., \& Wenstrom, J. (1994). Glucose effects on complex memory and nonmemory tasks: The influence of age, sex, and glucoregulatory response. Psychobiology, 22, 95-105.

Craft, S., Zallen, G., \& Baker, L. D. (1992). Glucose in mild senile dementia of the Alzheimer type. Journal of Clinical \& Experimental Neuropsychology, 14, 253-267.

Craik, F. I. M. (1977). Age differences in human memory. In J. E. Birren \& K. W. Schaie (Eds.), Handbook of the psychology of aging (pp. 384-420). New York: Van Nostrand Reinhold.

Drachman, D. A., \& LeavitT, J. (1972). Memory impairment in the aged: Storage versus retrieval deficit. Journal of Experimental Psychology, 93, 302-308

Fellows, M., Boutelle, G., \& Fillenz, M. (1993). Physiological stimulation increases nonoxidative glucose metabolism in the brain of the freely moving rat. Journal of Neurochemistry, 60, 1258-1263.

Folstein, M. F., Folstein, S. E., \& MCHugh, P. R. (1975). "Minimental state": A practical method for grading the cognitive state of 
patients for the clinician. Journal of Psychiatric Research, 12, 189198.

FranCIS, W. N., \& KuČERA, H. (1982). Frequency analysis of English usage: Lexicon and grammar. Boston: Houghton-Mifflin.

Gibson, G. E., \& Peterson, C. (1981). Aging decreases oxidative metabolism and the release and synthesis of acetylcholine. Journal of Neurochemistry, 37, 978-984.

GoLD, P. E. (1991). An integrated memory regulation system: From blood to brain. In R. C. A. Frederickson, J. L. McGaugh, \& D. L. Felten (Eds.), Peripheral signaling of the brain: Role in neural-immune interactions, learning and memory (pp. 391-419). Toronto: Hogrefe \& Huber.

GoLD, P. E. (1994). Modulation of emotional and non-emotional memories: Same pharmacological systems, different neuroanatomical systems. In J. L. McGaugh, N. M. Weinberger, \& G. S. Lynch (Eds.), Brain and memory: Modulation and mediation of neural plasticity (pp. 41-74). New York: Oxford University Press.

GoLD, P. E. (1995). The role of glucose in regulating brain and cognition. American Journal of Clinical Nutrition, 61, S987-S995.

Gold, P. E., VoGT, J., \& HaLL, J. L. (1986). Posttraining glucose effects on memory: Behavioral and pharmacological characteristics. Behavioral \& Neural Biology, 46, 145-155.

Graf, P., SQuire, L. R., \& MANDLER, G. (1984). The information that amnesic patients do not forget. Journal of Experimental Psychology: Learning, Memory, \& Cognition, 10, 164-178.

Hall, J. L., Gonder-Frederick, L. A., Chewning, W. W., SilVEIRA, J., \& GOLD, P. E. (1989). Glucose enhancement of memory in young and aged humans. Neuropsychologia, 27, 1129-1138.

Light, L. L., \& Singh, A. (1987). Implicit and explicit memory in young and older adults. Journal of Experimental Psychology: Learning, Memory, \& Cognition, 13, 531-541.

Manning, C. A., Hall, J. L., \& Gold, P. E. (1990). Glucose effects on memory and other neuropsychological tests in elderly humans. Psychological Science, 5, 307-311.

Manning, C. A., Parsons, M. W., \& Gold, P. E. (1992). Anterograde and retrograde enhancement of 24-hour memory by glucose in elderly humans. Behavioral \& Neural Biology, 58, 125-130.

ManNing, C. A., Ragozzino, M. E., \& Gold, P. E. (1993). Glucose enhancement of memory in patients with probable senile dementia of the Alzheimer's type. Neurobiology of Aging, 14, 523-528.

Manning, C. A., Stone, W. S., Korol, D. L., \& Gold, P. E. (1997). Glucose enhancement of 24-hour memory retrieval in healthy elderly humans. Manuscript in preparation.

MCANDrews, M. P., Glisky, E. L., \& Schacter, D. (1987). When priming persists: Long-lasting implicit memory for a single episode in amnesic patients. Neuropsychologia, 25, 497-506.

Musen, G., \& SQuire, L. R. (1992). Nonverbal priming in amnesia. Memory \& Cognition, 20, 441-448.

Packard, M. G., \& White, N. M. (1990). Effect of posttraining injections of glucose on acquisition of two appetitive learning tasks. $P_{s y-}$ chobiology, 18, 282-286.
Ragozzino, M. E., \& Gold, P. E. (1994). Task-dependent effects of intra-amygdala morphine injections: Attenuation by intra-amygdala glucose injections. Journal of Neuroscience, 14, 7478-7485.

Ragozzino, M. E., Parker, M. E., \& Gold, P. E. (1992). Memory impairments with morphine injections into the medial septum: Attenuation by glucose administration. Brain Research, 597, 241-249.

Ragozzino, M. E., UNick, K. E., \& Gold, P. E. (1996). Hippocampal acetylcholine release during memory testing in rats: Augmentation by glucose. Proceedings of the National Academy of Sciences, 93, 4693-4698.

RiCNY, J., Tucek, S., \& Novakova, J. (1992). Acetylcarnitine, carnitine and glucose diminish the effect of muscarinic antagonist quinuclidinyl benzilate on striatal acetylcholine content. Brain Research, 576, 215-219.

Schacter, D. L., Cooper, L. A., Tharan, M., \& Rubens, A. B. (1991). Preserved priming of novel objects in patients with memory disorders. Journal of Cognitive Neuroscience, 3, 118-131.

SIEGEL, S. (1956). Nonparametric statistics for the behavioral sciences. New York: McGraw-Hill.

Shimamura, A. P., Salmon, D. P., Squire, L. R., \& Butters, N. (1987). Memory dysfunction in dementia and amnesia. Behavioral Neuroscience, 101, 347-351.

SQuire, L. R., KNowlton, B., \& Musen, G. (1993). The structure and organization of memory. Annual Review of Psychology, 44, 453-495.

Squire, L. R., Shimamura, A. P., \& Graf, P. (1987). Strength and duration of priming effects in normal subjects and amnesic patients. Neuropsychologia, 25, 195-210.

StONE, W. S., RUdD, R. J., \& Gold, P. E. (1990). Amphetamine, epinephrine, and glucose enhancement of memory retrieval. Psychobiology, 18, 227-230.

Stone, W. S., Walser, B., Gold, S. D., \& Gold, P. E. (1991). Scopolamine- and morphine-induced impairments of spontaneous alternation performance in mice: Reversal with glucose and cholinergic and adrenergic agonists. Behavioral Neuroscience, 105, 264-271.

Tulving, E., \& SCHACTER, D. L. (1990). Priming and human memory systems. Science, 247, 301-306.

WANN, P. A., Ballard, L. A., \& LAdE, B. J. (1991). Sweet recall: Glucose enhancement of memory in middle-aged humans. Journal of Clinical \& Experimental Neuropsychology, 13, 18.

White, N. (1991). Peripheral and central memory-enhancing actions of glucose. In R. C. A. Frederickson, J. L. McGaugh, \& D. L. Felten (Eds.), Peripheral signaling of the brain: Role in neural-immune interactions and learning and memory (pp. 421-441). Toronto: Hogrefe \& Huber

Winocur, G., Moscovitch, M., \& STuss, D. T. (1996). Explicit and implicit memory in the elderly: Evidence for double dissociation involving medial temporal- and frontal-lobe functions. Neuropsychology, 10, 57-65.

(Manuscript received June 10, 1996; revision accepted for publication December 17,1996 .) 